\title{
To Evaluate the Efficacy of Heart Failure Reversal Therapy Using NT-Probnp Levels in Patients with Chronic Heart Failure
}

\author{
Sane Rohit, Mandole Rahul* \\ Department of Research and Development, Madhavbaug Cardiac Care Clinics and Hospitals, Mumbai, India \\ Email address: \\ drrahul@madhavbaug.org (M. Rahul) \\ *Corresponding author
}

To cite this article:

Sane Rohit, Mandole Rahul. To Evaluate the Efficacy of Heart Failure Reversal Therapy Using NT-Probnp Levels in Patients with Chronic Heart Failure. Cardiology and Cardiovascular Research. Vol. 2, No. 3, 2018, pp. 61-64. doi: 10.11648/j.ccr.20180203.13

Received: August 19, 2018; Accepted: October 10, 2018; Published: October 30, 2018

\begin{abstract}
Heart failure is considered as a life-threatening epidemic disorder affecting about 26 million world's population and associated with considerable morbidity, mortality and healthcare expenses. Despite the availability of a range of advanced treatments and sophisticated therapies the prevalence of heart failure represents a herculean challenge. To address the challenge, the current investigation was conducted by evaluating the efficacy of Heart Failure Reversal Therapy (HFRT) in reducing left ventricular distress by assessing N-terminal pro-brain natriuretic peptide (NT-proBNP) levels in congestive heart failure (CHF) patients. Total $76 \mathrm{CHF}$ patients with NYHA Class II and III were screened from March to May 2017 and 15 CHF patients with NT-proBNP $=300-1500 \mathrm{pg} / \mathrm{ml}$ were selected for the study. NT-proBNP is measured as a marker, the value of which increases with an increase in severity of CHF. The study therapy, HFRT comprises of traditional procedure of panchkarma that includes snehana (external oleation), swedana (passive heat therapy), hrudaydhara (concoction dripping treatment) and basti (medicated enema) was administered twice daily for 7 days. Post-HFRT, ARJ kadha was administered for next 12 weeks follow-up. NT-proBNP levels were measured after a follow-up period of 90 days along with some other parameters like $\mathrm{BMI} \mathrm{VO}_{2 \text { peak }}$ (evaluated by cardiac stress test with modified Bruce protocol) and weight. The findings of the investigation revealed significant reduction in NT-proBNP levels $(42.46 \%, \mathrm{p}=0.009)$, weight $(4.82 \%, \mathrm{p}=0.0007)$ and BMI $(3.67 \%, \mathrm{p}=0.034)$ at the end of the follow-up period. The study also yielded significant improvements in $\mathrm{VO}_{2 \text { peak }}(50.96 \%, \mathrm{p}=0.004)$. The overall results suggest that HFRT can possibly be explored as add-on therapy or a feasible alternative for the effective management of CHF.
\end{abstract}

Keywords: NT-proBNP, Chronic Heart Failure, Heart Failure Reversal Therapy

\section{Introduction}

Chronic Heart Failure (CHF) is a prevalent systemic disease affecting a significant proportion of the population worldwide. [1] Recently published INTER-CHF prospective cohort study reported India has $23 \%$ annual mortality rate owing to $\mathrm{CHF}$ alone. [2] Pioneering research studies have led to a change in the classic approach and development of new therapies which have ameliorated symptoms and improved the survival rate of patients with CHF. However, this chronic condition continues to remain a progressive disease causing incremental morbidity and early mortality. [3].

Owing to these exigencies, Heart Failure Reversal Therapy (HFRT), an Ayurvedic non-invasive therapy was designed to assist better survival outcomes in patients with heart failure. A randomized control trial has shown HFRT to be efficacious and safe in CHF patients with $30-65 \%$ ejection fraction (EF). [4] Another HFRT study (article in press) confirmed its effect at 90 days follow-up in $\mathrm{CHF}$ patients with reduced EF.

Along with development in the treatment of $\mathrm{CHF}$, it is equally important to have good diagnostic markers. Good diagnostic markers help in analysis of efficacy of treatment and/or disease progression etc. Recently, measurement of circulating levels of brain natriuretic peptide (BNP), a biologically active peptide of 32 amino acids with natriuretic properties, has become a potential diagnostic aid to identify patients with heart failure. $[5,6]$.

Upon secretion of BNP in response to left ventricular 
distress, proBNP (1-108) in cardiomyocytes is cleaved into the active hormone BNP (77-108) and inactive (1-76) N-terminal proBNP (NT-proBNP) [7]. As NT-proBNP has better stability, both in circulating blood and after sampling, it is considered to be an ideal marker for the detection and evaluation of chronic heart failure [7], pro-BNP levels are known to increase with an increase in the severity of CHF.

The main objective of this study was to evaluate the efficacy of HFRT in reducing left ventricular distress as assessed by NT-proBNP levels.

\section{Materials and Methods}

\subsection{Study Population}

CHF patients (male/female and aged between 40-70 yrs.) were screened from March to May 2017. Patients willing to participate in the study and belonging to New York Heart Association (NYHA) Class II and III with NT-proBNP levels $=300-1500 \mathrm{pg} / \mathrm{ml}$ were included in the study.

\subsection{Study Protocol}

At the baseline visit, all patients were examined by a physician, and the following information was obtained: medical history, including medications used; physical examination with measurements of height and weight; resting blood pressure; heart rate; and NYHA classification based on patient information. Patient then underwent study therapy i.e. HFRT and were followed up for a period of 90 days post-HFRT.

\subsection{Study Therapy}

HFRT is a therapeutic Ayurvedic treatment consisting of four major steps of Snehana, Sweden, Hrudaydhara, and Basti followed in the same order [4]. This procedure is performed twice in a day on patients with CHF for 7 consecutive days by trained and skilled staff. Along with HFRT, ARJ kadha (decoction of T. arjuna, A. calamus and B. diffusa) is also administered to the patient.

The current study included in the manuscript was conducted in accordance with the ethical principles of the Declaration of Helsinki, and all patients provided written informed consent.

\subsection{Study Parameters}

\subsubsection{Primary Endpoint}

NT-proBNP levels were measured before HFRT and after a follow-up period of 90 days. Venous blood was drawn into EDTA tubes and promptly centrifuged, and plasma was frozen at $-80^{\circ} \mathrm{C}$ until analysis of NT-proBNP was carried out. NT-proBNP was measured by a One-Step Test for NT-proBNP Colloidal Gold assay (Mex Biotech Hongkong Ltd).

\subsubsection{Secondary Endpoints}

Clinical status of the patients was assessed by evaluating improvements in $\mathrm{VO}_{2 \text { peak }}$ using cardiac stress test with modified Bruce protocol, and metabolic equivalents (METs) after and before follow-up period. MET is the ratio of metabolic rate (the rate of energy consumption) during a specific physical activity to a reference metabolic rate $(3.5 \mathrm{ml}$ $\mathrm{O}_{2} \mathrm{~kg}^{-1} \mathrm{~min}^{-1}$ ). [8] $\mathrm{VO}_{2 \text { peak }}$ is the measurement of the volume of oxygen that the body can utilize during physical exertion $\left(\mathrm{VO}_{2 \text { peak }}=\mathrm{MET}\right.$ value $\left.\times 3.6\right)$. [9] Additionally, EF was also evaluated.

\subsubsection{Statistical Analysis}

Normally distributed variable values are expressed as mean (SD). Other continuous variables are given as median and range. Differences in means between groups were compared using the t-test or an F test as appropriate, and differences in medians by the Mann-Whitney U test. All statistical analyses were done using Statistical Package for the Social Sciences (SPSS version 21.0).

\section{Results}

Seventy-six patients with CHF were screened during the study timeline and fifteen patients who were eligible according to the study screening protocol were enrolled. All the patients were successfully administered the study therapy.

Out of the fifteen patients with CHF, thirteen were males and the average age of the study population is 54.8 years (Table 1). A reduction in weight $(4.82 \%, \mathrm{p}=0.0007)$ and BMI $(3.67 \%, \mathrm{p}=0.034)$ was observed 90 days post-HFRT.

Table 1. Demographic and Clinical characteristics of patients with CHF.

\begin{tabular}{ll}
\hline Parameter & Before HFRT \\
Age (yrs.) & $54.8 \pm 7.57$ \\
Male & 12 \\
Female & 3 \\
Weight $(\mathrm{Kgs})$ & $64.54 \pm 9.8$ \\
BMI $\left(\mathrm{kg} / \mathrm{m}^{2}\right)$ & $24.45 \pm 2.61$ \\
\hline
\end{tabular}

There was a $42.46 \%$ reduction in NT-proBNP levels which is statistically significant $(p=0.009)$. Figure 1 shows the decrease in NT-proBNP levels post-HFRT therapy.

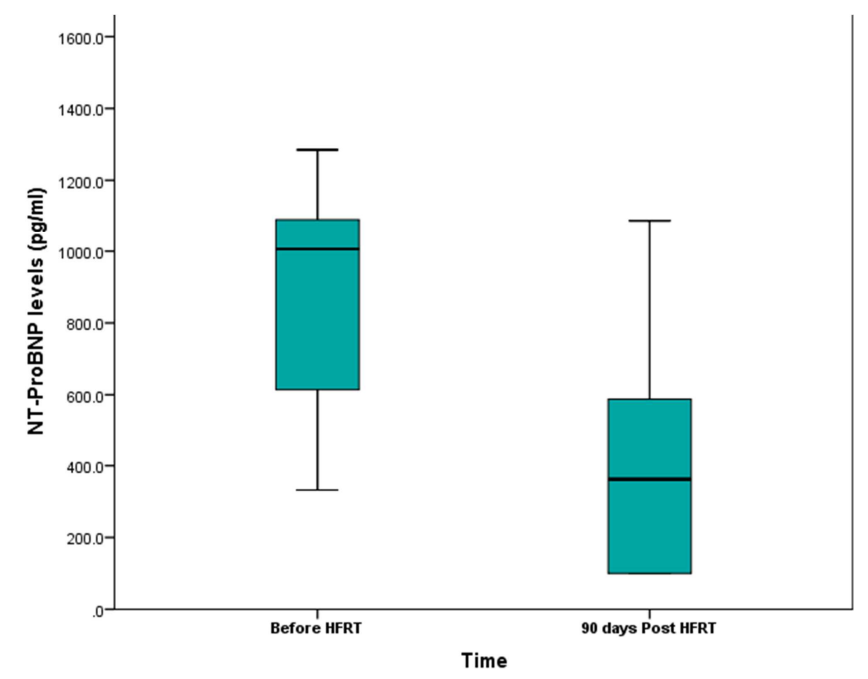

Figure 1. Reduction in NT-ProBNP levels. 
Table 2 shows the pre- and post-HFRT values for $\mathrm{VO}_{2 \text { peak, }}$, MET and EF. The study result shows a significant increase in $\mathrm{VO}_{2 \text { peak }}$ levels $(50.96 \%, \mathrm{p}=0.004)$. It hereby depicts an improvement in oxygen uptake capacity of the heart. However, the EF did not change significantly.

Table 2. Change in the levels of study parameters at 90 days of follow up post HFRT as compared with baseline.

\begin{tabular}{lll}
\hline Parameter & Before HFRT & 90 days post-HFRT \\
\hline NT-proBNP $(\mathrm{pg} / \mathrm{ml})$ & $858.47 \pm 320.84$ & $494.07 \pm 468.65(\mathrm{p}=0.009)$ \\
Metabolic Equivalent & $4.88 \pm 2.12$ & $7.37 \pm 1.71(\mathrm{p}=0.001)$ \\
$\mathrm{VO}_{2 \text { peak }}$ & $17.09 \pm 7.41$ & $25.80 \pm 5.99(\mathrm{p}=0.001)$ \\
Ejection Fraction & $49.92 \pm 11.61$ & $48.69 \pm 10.74$ \\
\hline
\end{tabular}

$\mathrm{VO}_{2 \text { peak: }}$ peak oxygen uptake.

The conventional drug dosage (namely ACE -inhibitors, anti-platelets, beta-blockers, calcium channel blockers and diuretics) used before HFRT was substantially lowered 90 days post-HFRT (Table 3).

Table 3. Concomitant medicine tapering post HFRT.

\begin{tabular}{lll}
\hline Concomitant medicines & $\begin{array}{l}\text { Before HFRT } \\
(\%)\end{array}$ & $\begin{array}{l}\text { 90 days } \\
\text { post-HFRT (\%) }\end{array}$ \\
\hline ACE inhibitor & 33.3 & 0 \\
Anti-platelet & 83.3 & 73.3 \\
Beta blocker & 60.0 & 53.3 \\
Calcium channel blocker & 26.6 & 20.0 \\
Diuretics & & \\
Thiazide & 6.7 & 6.7 \\
Loop & 6.7 & 0 \\
Potassium-sparing c & 26.7 & 26.7 \\
Pyridine-sulfonyl urea type loop & 33.3 & 26.7 \\
Others & 43.0 & 34.6 \\
\hline
\end{tabular}

ACE: Angiotensin converting enzyme.

\section{Discussion}

The important outcome as per our study result is the sustained efficacy of HFRT post 90 days of therapy administration. HFRT has been reported earlier [4] to be helpful in CHF patients but results of this study report its effect post 90 days using NT-proBNP as a diagnostic marker.

There has been a lot of literature published for the utility of NT-proBNP as a diagnostic marker in CHF patients. As a result, there is now growing evidence that among the BNPs, NT-proBNP is more accurate in reflecting myocardial wall tension. [10-14] Therefore, it is not only helpful in differentiating patients with normal LVEF and impaired LVEF but also a predictive diagnostic marker for HF and reduced survival at 10 years. [15] PARADIGM-HF trial even reports patients with a significant reduction in NT-proBNP had a lower subsequent rate of cardiovascular death or $\mathrm{HF}$ hospitalization. [16].

However, it has to be noted there is no single cut-off value depicting normal NT-proBNP level but an age-wise cut-off such as $450 \mathrm{pg} / \mathrm{mL}$ for $<50$ years, $900 \mathrm{pg} / \mathrm{ml}$ for $50-75$ years and $1,800 \mathrm{pg} / \mathrm{mL}$ for $>75$ years can be considered. [17] In the present study wherein, the mean age of the study population is about 55 years, a change in NT-proBNP levels from approximately $1000 \mathrm{pg} / \mathrm{mL}$ to $370 \mathrm{pg} / \mathrm{ml}$, ninety days post-HFRT is remarkable. This reduction in NT-proBNP levels shows the improvement in heart functioning of the study population thereby reflecting the beneficial effect of HFRT. Furthermore, there is a reduction in conventional treatment drug dosage observed post-HFRT thereby underlining its value as an add-on therapy.

\section{Conclusion}

In contrast to the ample amount of literature showing the efficacy of Chinese and other alternative therapies in patients with CHF there is paucity of evidence-based studies in Ayurveda. This study is the best amalgamation of diagnostic science and Ayurveda. The results of present study reflect benefits of an wholesome Ayurvedic treatment in patients with CHF with a follow-up of 90 days. Although the study population is small, the results show promising hope for the role of Ayurveda based alternative medicine in aiding $\mathrm{CHF}$ patients. Therefore, more studies and/or rigorously designed RCTs are warranted to establish the efficacy of HFRT as an add-on to the conventional treatment.

\section{Acknowledgements}

The authors thank Poonam Pawar for writing assistance and editorial support for this manuscript.

\section{Disclosures}

Dr. Rohit Sane and Dr. Rahul Mandole received remuneration from the funding source i.e. Vaidya Sane Ayurvedic Education and Agricultural Trust.

\section{References}

[1] Metra M, Teerlink JR (2017) Heart failure. Lancet 6736:. doi: 10.1016/S0140-6736(17)31071-1.

[2] Dokainish H, Teo K, Zhu J, et al (2017) Global mortality variations in patients with heart failure: results from the International Congestive Heart Failure (INTER-CHF) prospective cohort study. Lancet Glob Heal 5:e665-e672. doi: 10.1016/S2214-109X(17)30196-1.

[3] Ramani G V., Uber PA, Mehra MR (2010) Chronic heart failure: Contemporary diagnosis and management. Mayo Clin Proc 85:180-195. doi: 10.4065/mcp.2009.0494.

[4] Sane R, Aklujkar A, Patil A, Mandole R (2017) Effect of heart failure reversal treatment as add-on therapy in patients with chronic heart failure: A randomized, open-label study. Indian Heart J 69:299-304. doi: 10.1016/j.ihj.2016.10.012.

[5] Troughton RW, Frampton CM, Yandle TG, et al (2000) Treatment of heart failure guided by plasma aminoterminal brain natriuretic peptide (N-BNP) concentrations. Lancet 355:1126-1130. doi: 10.1016/S0140-6736(00)02060-2. 
[6] Redfield MM (2004) Plasma Brain Natriuretic Peptide to Detect Preclinical Ventricular Systolic or Diastolic Dysfunction: A Community-Based Study. Circulation 109:3176-3181. doi: 10.1161/01.CIR.0000130845.38133.8F.

[7] Vanderheyden M, Bartunek J, Goethals M (2004) Brain and other natriuretic peptides: Molecular aspects. Eur J Heart Fail 6:261-268. doi: 10.1016/j.ejheart.2004.01.004.

[8] Jetté M, Sidney K, Blümchen G (1990) Metabolic equivalents (METS) in exercise testing, exercise prescription, and evaluation of functional capacity. Clin Cardiol 13:555-565. doi: 10.1002/clc.4960130809.

[9] Coelho-Ravagnani C de F, Lemos Melo FC, Ravagnani FCP, et al (2013) Estimation of the metabolic equivalent (MET) of an exercise protocol based on indirect calorimetry. Rev Bras Med do Esporte 19:134-138. doi: 10.1590/S1517-86922013000200013.

[10] Yamamoto K, Burnett JC, Jougasaki M, et al (1996) Superiority of Brain Natriuretic Peptide as a Hormonal Marker of Ventricular Systolic and Diastolic Dysfunction and Ventricular Hypertrophy. Hypertension 28:988 LP-994.

[11] Omland T, Aakvaag A, Bonarjee VVS, et al (1996) Plasma Brain Natriuretic Peptide as an Indicator of Left Ventricular Systolic Function and Long-term Survival After Acute Myocardial Infarction. Circulation 93:1963 LP-1969.

[12] Davidson NC, Naas AA, Hanson JK, et al (1996) Comparison of atrial natriuretic peptide B-type natriuretic peptide, and $\mathrm{N}$-terminal proatrial natriuretic peptide as indicators of left ventricular systolic dysfunction. Am J Cardiol 77:828-831. doi: 10.1016/s0002-9149(97)89176-x.

[13] McDonagh TA, Robb SD, Murdoch DR, et al (1998) Biochemical detection of left-ventricular systolic dysfunction. Lancet 351:9-13. doi: 10.1016/S0140-6736(97)03034-1.

[14] Jolobe O (1995) Detection of left ventricular dysfunction after myocardial infarction: comparison of clinical, echocardiographic, and neurohormonal methods. Br Heart J 73:101-102.

[15] Bay M, Kirk V, Parner J, et al (2003) NT-proBNP: a new diagnostic screening tool to differentiate between patients with normal and reduced left ventricular systolic function. Heart 89:150-4. doi: 10.1136/heart.89.2.150.

[16] Vardeny O, Claggett B, Packer M, et al (2016) Efficacy of sacubitril / valsartan vs. enalapril at lower than target doses in heart failure with reduced ejection fraction: the PARADIGM-HF trial with ACEI to Determine Impact on Global Mortality and Morbidity in Heart. Eur J Heart Fail 1-7.

[17] Januzzi JL, Van Kimmenade R, Lainchbury J, et al (2006) NT-proBNP testing for diagnosis and short-term prognosis in acute destabilized heart failure: An international pooled analysis of 1256 patients: The international collaborative of NT-proBNP study. Eur Heart J 27:330-337. doi: 10.1093/eurheartj/ehi631. 